\title{
Assessing Sustainable Food and Nutrition Security of the EU Food System-An Integrated Approach
}

\author{
Monika Zurek ${ }^{1, *(\mathbb{D}}$, Aniek Hebinck ${ }^{1,2} \mathbb{D}$, Adrian Leip ${ }^{3} \mathbb{C}$, Joost Vervoort ${ }^{1,4}$, Marijke Kuiper ${ }^{5}$, \\ Maria Garrone ${ }^{6}{ }^{\circledR}$, Petr Havlík ${ }^{7}$, Thomas Heckelei ${ }^{8}$, Sara Hornborg ${ }^{9}$, John Ingram ${ }^{1}(\mathbb{D}$, \\ Anneleen Kuijsten ${ }^{10} \odot$, Lindsay Shutes ${ }^{5}$, Johanna M. Geleijnse ${ }^{10} ®$, Ida Terluin ${ }^{5}$, \\ Pieter van 't Veer ${ }^{10}$, Jo Wijnands ${ }^{5,+}$, Andrea Zimmermann ${ }^{8,11}$, and Thom Achterbosch ${ }^{5}$ \\ 1 Environmental change Institute, University of Oxford, Oxford OX1 3QY, UK; aniek.hebinck@su.se (A.H.); \\ j.m.vervoort@uu.nl (J.V.); john.ingram@eci.ox.ac.uk (J.I.) \\ 2 Stockholm Resilience Centre, Stockholm University, 10405 Stockholm, Sweden \\ 3 European Commission, Joint Research Centre, I-21027 Ispra (VA), Italy; adrian.leip@ec.europa.eu \\ 4 Copernicus Institute of Sustainable Development, University of Utrecht, 3584 CB Utrecht, The Netherlands \\ 5 Wageningen Economic Research, 2595 BM The Hague, The Netherlands; marijke.kuiper@wur.nl (M.K.); \\ lindsayjshutes@gmail.com (L.S.); ida.terluin@wur.nl (I.T.); thom.achterbosch@wur.nl (T.A.) \\ 6 LICOS-Centre for Institutions and Economic Performance, KU Leuven University, 3000 Leuven, Belgium; \\ maria.garrone@kuleuven.be \\ 7 Ecosystems Services and Management Program, International Institute for Applied Systems Analysis, \\ 2361 Laxenburg, Austria; havlikpt@iiasa.ac.at \\ 8 Institute for Food and Resource Economics, University of Bonn, 53115 Bonn, Germany; \\ thomas.heckelei@ilr.uni-bonn.de (T.H.); andrea.zimmermann@fao.org (A.Z.) \\ 9 Agrifood and Bioscience, RISE Research Institutes of Sweden, 40229 Gothenburg, Sweden; \\ sara.hornborg@ri.se \\ 10 Division of Human Nutrition and Health, Wageningen University, 6700 AA Wageningen, The Netherlands; \\ anneleen.kuijsten@wur.nl (A.K.); marianne.geleijnse@wur.nl (J.M.G.); pieter.vantveer@wur.nl (P.v.V.) \\ 11 Trade and Markets Division, Food and Agriculture Organization of the United Nations, 00153 Rome, Italy \\ * Correspondence: monika.zurek@eci.ox.ac.uk; Tel.: +44-(0)1865-285531 \\ + Jo Wijnands passed away.
}

Received: 29 September 2018; Accepted: 13 November 2018; Published: 19 November 2018

check for check for
updates

\begin{abstract}
Steering the EU food system towards a sustainability transformation requires a vast and actionable knowledge base available to a range of public and private actors. Few have captured this complexity by assessing food systems from a multi-dimensional and multi-level perspective, which would include (1) nutrition and diet, environmental and economic outcomes together with social equity dimensions and (2) system interactions across country, EU and global scales. This paper addresses this gap in food systems research and science communication by providing an integrated analytical approach and new ways to communicate this complexity outside science. Based on a transdisciplinary science approach with continuous stakeholder input, the EU Horizon2020 project 'Metrics, Models and Foresight for European SUStainable Food And Nutrition Security' (SUSFANS) developed a five-step process: Creating a participatory space; designing a conceptual framework of the EU food system; developing food system performance metrics; designing a modelling toolbox and developing a visualization tool. The Sustainable Food and Nutrition-Visualizer, designed to communicate complex policy change-impacts and trade-off questions, enables an informed debate about trade-offs associated with options for change among food system actors as well as in the policy making arena. The discussion highlights points for further research related to indicator development, reach of assessment models, participatory processes and obstacles in science communication.
\end{abstract}


Keywords: food systems; metrics; interdisciplinarity; sustainable food and nutrition security; food system assessment; participatory approach; SUSFANS

\section{Introduction}

Food systems are complex entities, described as consisting of many different actors, their activities and interactions, the driving forces shaping these activities and the outcomes produced at the individual and system's level. This complexity makes it difficult to analyze, govern or change food systems. As such, food systems research asks for an integrated approach for analysis and new ways to communicate this complexity outside the research domain [1,2]. Food systems currently do not deliver the expected food and nutrition security outcomes, have many social inequalities embedded in them and are regarded as a major driver of global environmental change [3-5]. The need to change our food systems to be more sustainable (including in health, environmental, social and economic terms) is widely acknowledged in research and policy circles [6-9]. Governance is considered an important lever in changing these systems to becoming more sustainable and to reaching these goals [10-14], but food systems encompass many different actors, each with their own set of driving forces and goals [15-17]. These need to be considered when discussing and negotiating change in the system. To govern effectively, decision makers need both an understanding of food systems elements and the effect policy, financial, or technical innovations (e.g., new technologies, measures to change consumer behavior) might have on specific actors as well as overall food system outcomes. Only then a differentiated debate across food system actors and policy makers and actors on what type of systems' change is needed and desirable will be enabled.

In this paper we present an integrated approach to food systems assessments applied to the European Union. This approach was developed as a basis for the work of the Horizon2020 EU-funded project 'Metrics, Models and Foresight for European SUStainable Food And Nutrition Security' (SUSFANS, www.susfans.eu). SUSFANS' overall objective is to develop the conceptual understanding, tools, foresight work and the evidence base to inform EU-wide and member state food and agriculture policies towards a transformation of the food system with respect to its impacts on public health, nutrition and diets, environmental, economic and social outcomes. Central to the project's approach is the assessment of the status of sustainable food and nutrition security (SFNS) in the EU and innovation options for enhancing SFNS in the EU. SFNS can be defined as the capacity of a food system to deliver food and nutrition security in an environmentally, economically and socially sustainable manner. This concept combines nutrition and health with a social-ecological systems perspective. The project aims to contribute to an integrated analysis of and effective decision making for food system change in the EU and its member states [2].

This paper is the first in a series of papers that describe the project work with respect to assessing food system status and transformation options. Here we lay out the conceptual foundations and steps of the project's approach. Subsequent papers will describe food system metrics work in more detail and how the approach was operationalized for the EU and for the project's four case study countries. These papers will also describe the experiences and challenges with the approach. This paper is structured as follows: After exploring what SFNS entails, we present a set of coherent steps that can enable an integrated debate around food systems change. This includes the creation of a participatory space; the development of a conceptual framework for mapping the EU food system (we recognize that there is no 'EU food system' as such, but rather that it is a set of local, regional, national and global interconnected systems and dynamics. We are using the term as a catch all term for the interlocked systems and their actors that put food on people's plates within the geographical unit that is the EU); the development of a set of metrics to assess SFNS and innovation pathways for food system change; the development of a modelling strategy based on the metrics; and the design of an integration and visualization tool across the metrics particularly geared towards policy makers. The steps are 
illustrated by the work done in the SUSFANS project (hereafter referred to as 'the project') to show how the conceptual approach could be operationalized.

\section{Defining Sustainable Food and Nutrition Security}

Debates on how to define and achieve food security have shifted substantially over the last decades. Various terms and terminologies have been used to capture the complexities of describing the outcomes of a food system. These terms have come from different scientific disciplines, such as the agricultural, development, or nutrition communities, and reflect the main discourses prevalent at the time. Born out of the experiences of the famines after the Second World War, the definition of food security focused on the supply of enough food and, thus, efforts to achieve it mainly emphasized increasing agricultural production, specifically around staple foods [18-20]. The work of Amartya Sen added the notion of entitlements to food, emphasizing accessibility, availability, affordability and utilization of food $[21,22]$. The nutrition community complemented the discussion on food security by emphasizing the need for an adequate nutritional status (in terms of under and over nutrition) in the 1990s [23,24], thus enlarging the concept by bringing in micro-level aspects of nutrition and health and becoming more applicable for nutrition planning. With the realization of the environmental footprint of our food system, the notion of 'sustainable diets' [13,25-31] describes the individual diet and its associated environmental sustainability implications, calling for a better matching of food consumption patterns with their environmental impacts. Since the 2000s, the question of how to change agriculture has evolved into the notion of how to govern and change a complex system of interconnected food actors (including farmers, food processors, retailers, consumers, and more). In short, aiming to put enough calories on people's plates as the key food security goal has morphed into several goals that encompass nutritional adequacy, environmental issues as well as economic, livelihoods and equity considerations. The SUSFANS project acknowledges this variety of goals for today's food systems in the notion of 'sustainable food and nutrition security'.

The 'food system' concept is increasingly used today as a conceptual and analytical tool to describe the processes and actors in the food sector. A food system is made up of food system activities (growing, harvesting, processing, packaging, transporting, marketing, consuming, and disposing of food and food-related items), and food system actors, all influenced by certain 'drivers' (processes determining how these activities are performed). These activities by actors in the food system, result in a number of outcomes, that, in turn, feed back to environmental and socio-economic drivers [15,17,32-34]. A food systems approach is "seen as the most effective strategy to enhance [food and] nutrition security in a more sustainable manner" [24], for two main reasons. First, by focusing on impacts and leverage points in the different domains it allows for an integrated assessment. Second, and building on the first, through this integrated assessment it can provide a framework to structure the debate of a complex issue [15].

Central to the integrated food system approach presented in this paper is 'Sustainable Food and Nutrition Security' (SFNS). This partly captures earlier work around food systems that embodies divergent theoretical and ontological framings $[35,36]$ and allows for the embedding of sustainability dimensions into the evaluation of the food systems. This means that the approach also includes the assessment of environmental, social and economic outcomes of the food system. One of the core objectives of this integrated approach here is to support EU decision makers in fostering the EU food policy goals described in various EU, member stated and food industry policies for the EU food system. These are: (1) Deliver a balanced healthy diet to consumers, (2) reduce the systems' negative environmental impact, (3) build a viable, competitive and socially balanced agri-food sector, and (4) contribute to social equity goals and global food security.

\section{An Integrated Approach}

Answering questions on how to achieve sustainable food and nutrition security, which is a multi-faceted concept, requires answers that are built on the insights that various disciplines (e.g., nutritional, agricultural, economic, social sciences, etc.) can bring to the table and the development 
of integrative tools that bring these together in accessible ways. In addition, the options for change need to be grounded in the realities of the actors within the system as they need to be implementation partners for new solutions.

A commonly used tool to communicate the status of a complex system — such as a food system-is the use of indicators $[23,24,37]$. They are regarded as functional information tools that can indicate the state of a certain policy goal, as they harness systems' complexities by making data insightful to people outside a certain research discipline [24,38]. Ranging from descriptive (pure data) to aggregated (consisting of multiple indicators) indicators, they are used to explain "a given situation or underlying reality which is difficult to quantify directly" [19]. The development of improved metrics and data for the assessment of food systems is essential to better inform policymakers [39]. While there is a general impression that indicators reflect reality and are 'neutral', assumptions embedded in underlying conceptual frameworks remain hidden. Especially when indicators are developed by experts alone the process can be opaque, not allowing for stakeholder-input $[38,40]$. Without transparency on the construction of indicators, they have the potential to become a tool of control to the already powerful, rather than empower all stakeholders.

The project developed several steps to deliver an integrated approach for assessing SFNS of the EU food system and innovation options for food system transformation. These included:

1. The creation of a participatory space;

2. The development of a conceptual framework mapping out the driving forces, actors, outcomes and goals for the EU food system [41];

3. An approach to devising a set of performance metrics for assessing the food system's status with respect to achieving SFNS and innovation options across four key policy goals formulated by food system actors [42];

4. A modelling strategy for quantifying the sustainability status of FNS in the EU [43];

5. A visualization tool that allows food system actors to assess the outcomes and associated trade-offs of possible innovation options in an integrated manner across the policy goals (the SFNS visualizer) [44].

\subsection{Step 1: The Creation of a Participatory Space}

To achieve a food system assessment that can be an aid for decision making, it is essential to create a participatory space $[45,46]$, ideally involving the decision makers in the discussions. This includes building on the knowledge, experiences and values of the many actors embedded in the system. Creating a participatory space can be done in various ways but it is important that the stakeholders come together from all over the food system and represent varying 'environments' and world views.

We invited a broad range of stakeholders in the EU food system into a so-called Stakeholder Core Group that acted as an advisory group to the project, reviewing and refining research ideas, the case study work and preliminary results. The selection was done based on an initial mapping of the EU food system while preparing the project's conceptual framework. The group consisted of the three main types: Actors associated with food systems activities, food system policy makers, and food system influencers (also see Figure 1 for details). The actual group consisted of 30 selected experts and decision makers representing primary producers, the food industry, retail, consumer groups, investors, regulators, policymakers and academics. The Stakeholder Core Group was brought together in four annual, interactive workshops in which the team discussed and received input on ideas and on-going work, particularly on the project's conceptual framework, metrics selection, case studies on innovation options and foresight work (Details on the project's stakeholder engagement work can be found on the project website, work package 6 . www.susfans.eu). The input was then brought back into the research design and shaped various research outputs (e.g., the stakeholders suggested to establish equity considerations as one of the food system policy goals. This suggestion was then brought into 
the conceptual framework design, metrics work and visualizer). As such, the involvement of the Stakeholder Core Group was an intricate part of the project.

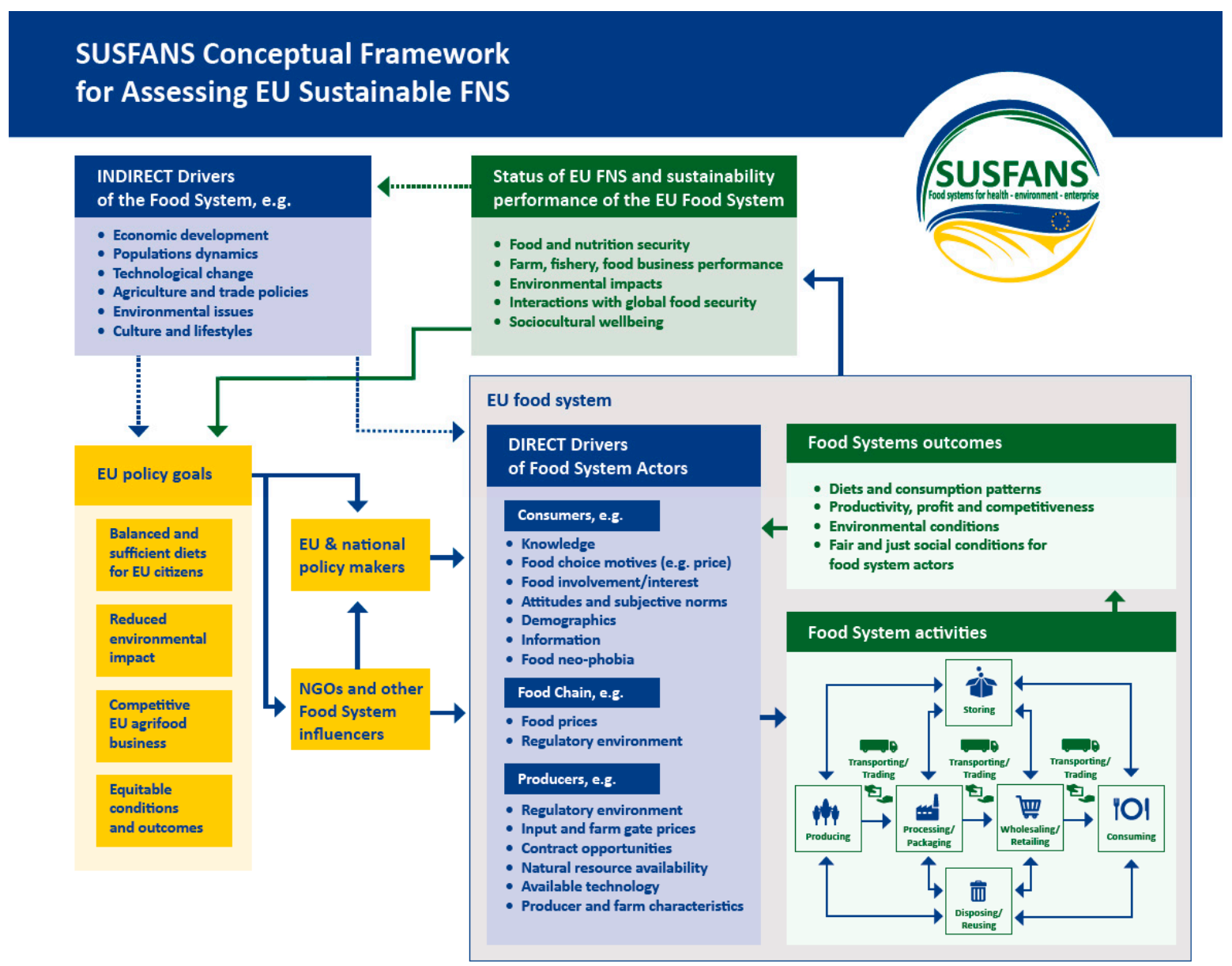

Figure 1. A visual representation of the conceptual framework that was developed based on an iterative consultation process with the Stakeholder Core Group.

\subsection{Step 2: A Conceptual Framework of the Food System}

As the food system is a complex system and consists of various elements, a prerequisite for a proper analysis and the assessment of its status is a conceptual framework that ensures that all the important elements of the system are included. The framework provides a logical structure for analysis together with a visual and written representation of the system, gives appropriate weight to its components and shows important assumptions about the interactions within the system as well as gaps in understanding. The most important purpose of the conceptual framework is to visualize the joint understanding of the food system across academics as well as stakeholders to provide a common ground for the interdisciplinary work of the project team as well as for the stakeholder work. The framework helps to identify possible entry points for improving system's performance and outcomes.

The conceptual framework (see Figure 1) was created with the input of all the scientific partners and discussed in detail with the Stakeholder Core Group (Details on the project's stakeholder engagement work can be found on the project website, work package 6. www.susfans.eu). For that, the project team provided the Core Group with a basic set up which was then populated, discussed and revised jointly in interactive meetings. The stakeholder core group was later also consulted about the chosen metrics (Step 3) whose selection depended on the conceptual framework. The basic components of the conceptual framework (Figure 1) describing the EU food system are (a detailed description of the conceptual framework can be found in project deliverable D1.1 on the website: www.susfans.eu): 
- The diverse sets of actors that are connected to the EU food system;

- The direct and indirect factors driving the behavior of food system actors and therefore influencing change within the food system (drivers of change);

- The outcomes that are related to the EU food system and its activities;

- The goals at the EU level that are shaping the drivers and the EU wide and national policies affecting the food system;

- The interactions and feedback loops that take place among the aforementioned food system components.

Ultimately, the framework allows for the identification of a wide set of policy and technical recommendations which can be assessed not just against a number of specific objectives or for specific actors, but which can also be examined against their effects when rippling through the whole system and their resulting potential unintended consequences/trade-off effects. Furthermore, the framework is intended to highlight the dynamic aspects of the system by laying out the system's drivers as well as the system's interactions and various feedback mechanisms.

\subsection{Step 3: Sustainability Metrics for Assessing the Food System and Innovation Options}

A meaningful set of metrics to assess the performance of a food system as well as how the system might transform with the introduction of possible innovations must give information with respect to one or more system elements, ideally as presented in the conceptual framework. The project decided in consultation with its Stakeholder Core Group to focus on the four policy goals as laid out in the conceptual framework. The group wanted to understand how close the current system is to achieving SFNS, defined in the four goals, and what possible innovations would do to help achieve the goals. To that end, the project developed a Hierarchical Approach with four different layers (Figure 2). The hierarchical approach intends to combine the idea that decision makers prefer a small, yet comprehensive set of metrics that can communicate findings of an assessment, together with the need to base these metrics on data from many sources that are easily accessible in a transparent way. The hierarchy of the approach is depicted in Figure 2, using the following terminology:

- Individual variable: A measure that can be quantified and/or counted in commonly used standards (e.g., hectares, $\mathrm{kg}$ ).

- Derived variable: Combines a number of individual variables to devise a new measure (e.g., nitrogen input vs. output, ratio of energy intake vs. expenditure,). Sometimes additional information is required to derive the variable (e.g., conversion of individual Greenhouse Gas Emissions to total $\mathrm{CO}_{2}$ equivalents).

- Aggregate indicator: Combines one or several derived variables and assesses them against a particular goal (e.g., marine biological diversity, reduction of nitrogen surplus, food access).

- Performance metric: Combines a number of aggregated indicators and evaluates them against performance of EU goals (e.g., climate stabilization, balanced diet for EU citizens).

The sets of performance metrics describing each policy goal are described in Table 1. A draft set of individual and derived variables, substantiating the aggregate indicators and performance metrics, as well as objectives for aggregate indicators is given in Reference [42]. 


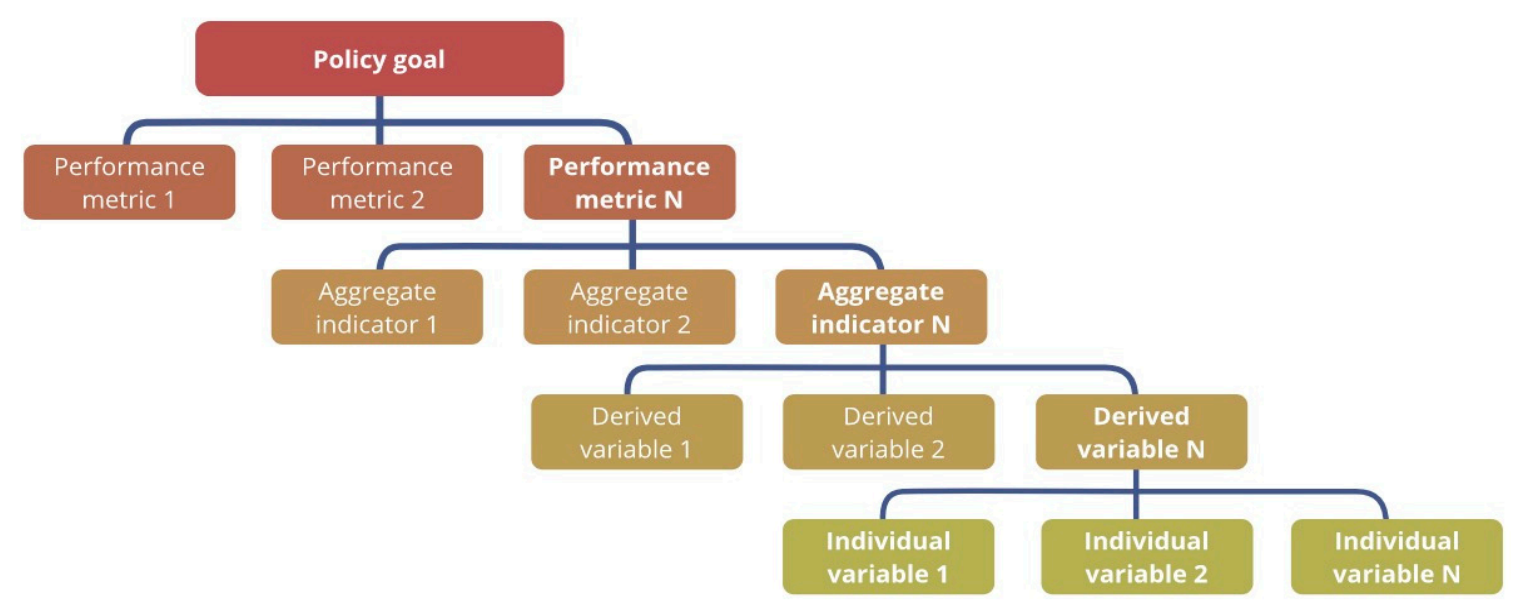

Figure 2. Visualization of the layers that make up the hierarchical approach to devising performance metrics in the Horizon2020 EU-funded project 'Metrics, Models and Foresight for European SUStainable Food And Nutrition Security' (SUSFANS) project. ' $\mathrm{N}$ ' indicates that the number of variables, indicators and metrics can vary per policy goal.

Table 1. The policy goals used by the project to describe sustainable food and nutrition security (SFNS) and their underlying performance metrics. For a full set of metrics, showing the full hierarchal approach, see Reference [42].

\begin{tabular}{ll}
\hline \multicolumn{1}{c}{ Policy Goals } & \multicolumn{1}{c}{ Performance Metrics } \\
\hline 1. Balanced and sufficient diets for EU citizens & $\begin{array}{l}\text { Food based intake summary } \\
\text { Nutrient based intake summary } \\
\text { Energy balance }\end{array}$ \\
\hline \multirow{2}{*}{$\begin{array}{l}\text { 2. Reduced environmental impacts of the EU } \\
\text { food system }\end{array}$} & $\begin{array}{l}\text { Climate stabilization } \\
\text { Clean air and water } \\
\text { Biodiversity conservation } \\
\text { Preservation of natural resources }\end{array}$ \\
\hline \multirow{3}{*}{ 3. Competitiveness of EU agri-food businesses } & $\begin{array}{l}\text { Relation between production and trade } \\
\text { Orientation and specialization of trade } \\
\text { Economic performance and productivity }\end{array}$ \\
\hline \multirow{2}{*}{$\begin{array}{l}\text { Equitable outcomes and conditions of the } \\
\text { EU food system }\end{array}$} & $\begin{array}{l}\text { Between producers and chain actors } \\
\text { Among consumers with regards to system conditions } \\
\text { Among consumers with regards to system outcomes } \\
\text { Footprint of food }\end{array}$ \\
\hline
\end{tabular}

\subsection{Step 4: Modelling Strategy for Quantifying Performance Metrics for the Food System}

Quantification and modelling of the metrics allows for a ground-truthing in available data and establishing relationships across different metrics. However, current models have either a specific focus on one section of a food system or do not cover all the different parts, such as seafood production [47]. Especially the latter is a major gap in food system assessments, as most modelling efforts up to date focus on crop and livestock production, often excluding seafood. Using the integrated set of metrics to assess SFNS in food systems in a forward-looking manner requires an integrated modelling strategy that is currently missing. Thus, existing models with different characteristics and that can produce different sets of outputs related to SFNS need to be connected in order to achieve a full picture of the integrated set of metrics developed in consultation with the stakeholders.

In the project, this was done by building on already existing state-of-the art models such as MAGNET [48], DIET [49], CAPRI [50,51] and GLOBIOM [52,53] and the development of a new tool to define model diets that perform well on sustainability and health objectives (SHARP) [54]. However, each of these have been developed to serve a specific sectoral policy-e.g., CAPRI has been developed 
for the EU agricultural policy, and DIET was designed for the purpose of assessing the social welfare impact of dietary change in the population at country level (see Figure 3). Taken separately, they are not designed for integrated assessments such as we argue for in this paper. Using the models in combination allows a consistent assessment across the different domains covered by each individual model. In addition, the combined models better capture diets, include seafood production and aim to portray synergies between sustainability and nutrition outcomes. For more detailed information about the developed integrated modeling strategy see References [55,56]. Regardless, three important deficiencies for food system assessment remain, namely actors behaving rationally by responding to 'perfect information' (see Section 4) are key for the models, food chain actors are not well represented in all models, and not all metrics can so far be quantified.

Conscious of the deficiencies that are embedded in the different modelling tools and data availability (more on this in Section 4), a modelling toolbox has been developed. This toolbox serves mainly for forward looking exercises. It combines the economy-wide but aggregate assessments of MAGNET with the European detail in CAPRI, and environmental assessments of GLOBIOM for consistent projections of developments in the global food system. Results in terms of prices, income and sustainability indicators are mapped to DIET for assessing consumer utility and to evaluate social welfare impact, and to SHARP to assess at detailed product level the nutrition, health and sustainability of diets. The toolbox also allows a reverse set-up, where an optimal diet derived by SHARP is imposed in the other models to assess the food system changes it implies at aggregate level.

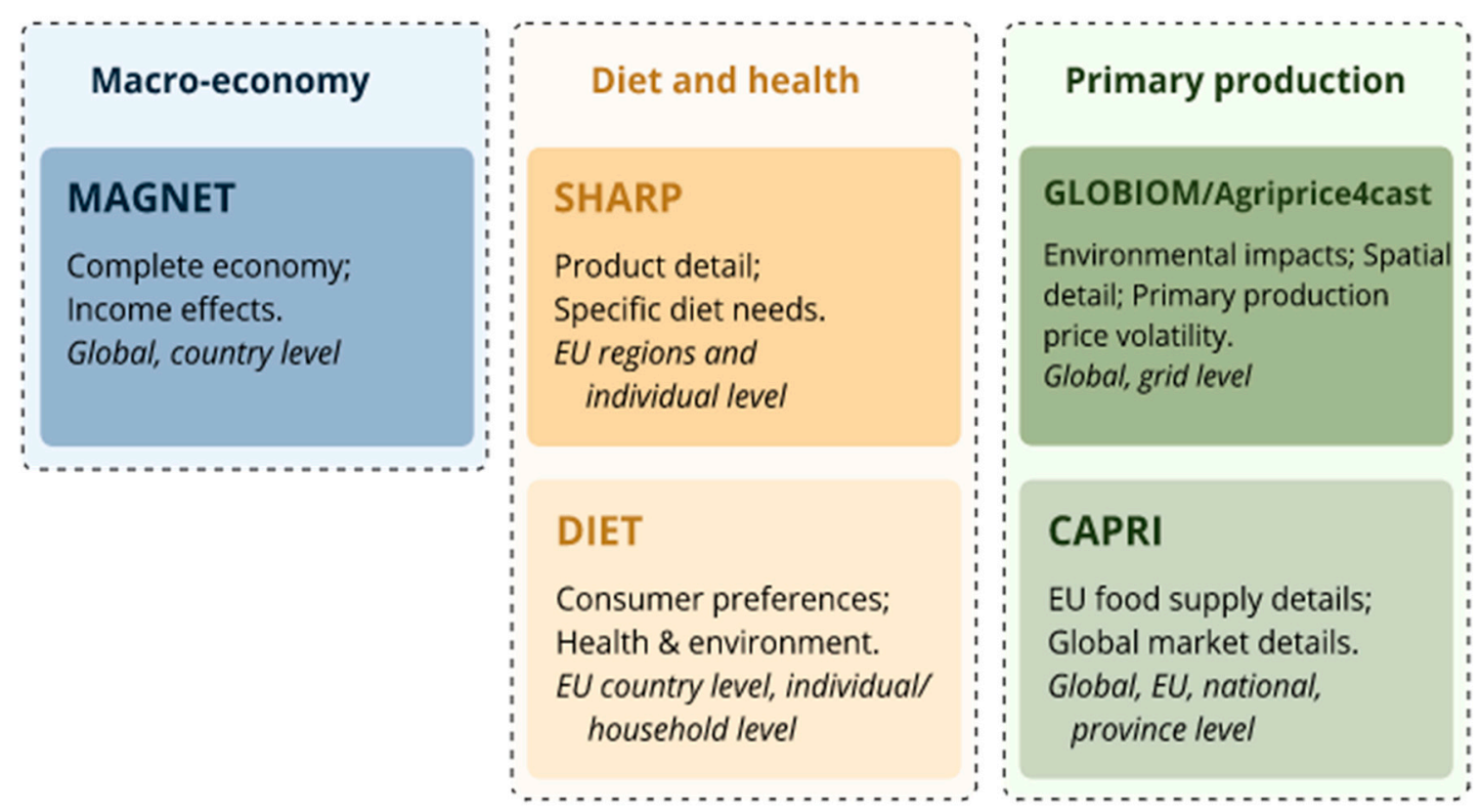

Figure 3. Existing models with different characteristics used to achieve a full picture of the integrated set of food system assessment metrics. The figure indicates differences between the models in terms of sectors (economy, diet, or production), differences in focus within these sectors and the scale level of their assessment.

\subsection{Step 5: Integration Across Metrics: The SUSFANS SFNS-Visualizer}

The last step is to visualize change in the status of SFNS of the food system. Making trade-offs visible and transparent is vital for decision making. A systemic perspective allows for evaluation of how particular actions or decisions could affect people or dynamics in different ways, and what trade-offs are key to making decisions on moving forward into more sustainable trajectories [57]. One of the key objectives of the SFNS visualizer is to communicate the systems complexities embedded in the SUSFANS sustainability assessment framework to a non-technical audience. The tool informs a discussion about the current sustainability performance of the EU food system, and pathways 
for transforming the EU food system by means of public and private policy reform and innovation. In doing so, it can highlight potential synergies between several goals in the EU food systems, while avoiding trade-offs. As such, the decision maker can see the potential impact for the key goal they are interested in, as well as for the other goals associated with sustainable food system change. An interactive spider diagram called the 'SFNS visualizer' was developed (see Figure 4), aiming to:

- Show the status of the EU food system with respect to policy goals today;

- Allow the user to look across all policy goals at the same time;

- Allow the user to assess changes to the food system's performance when introducing innovations;

- Visualize synergies and trade-offs across policy goals for the selected innovations to enable an informed discussion about which innovations to pursue.

Figure 4 depicts a mock-up of the visualizer showing a hypothetical assessment of the current status of the EU food system. The visualizer is constructed through the aggregation of variables and indicators into performance metrics as described in the hierarchical approach in Step 3, see Figure 5. The closer the red wedge in the middle gets to the performance metrics (i.e., the bigger the wedge gets) the closer the food system gets towards achieving the formulated goals and their targets. The hypothetical assessment shows, for example, that the project hypothesized that the EU is doing relatively well with respect to a healthy diet and the food sector is quite competitive, while the food system nevertheless produces high environmental impacts and could improve with respect to equity considerations (the on-going modelling work is testing these hypotheses). If innovations are introduced to the system (e.g., changes in fishery practices, more stringent nutrient management in livestock systems or social innovations that help reduce food waste) these will result in changes in one or more food system outcomes, i.e., red wedges. This will allow the user to see the effect of a particular innovation option across all policy goals, thus visualizing synergies and trade-offs across policy goals.

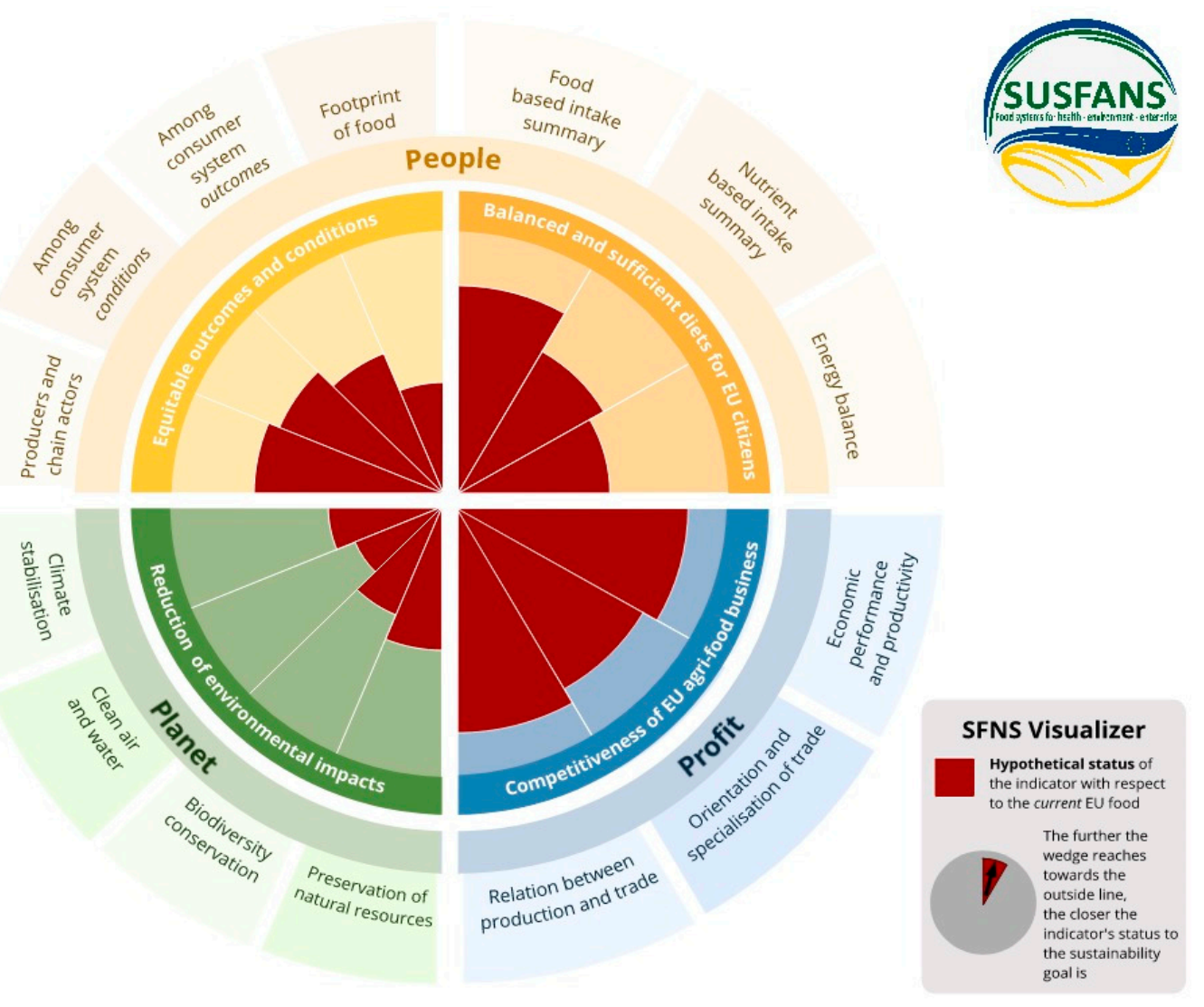

Figure 4. The SUSFANS SFNS-impact visualizer showing a hypothetical assessment of the current EU food system's SFNS status. 
How the assessment shown in the visualizer is constructed through the aggregation of variables and indicators, as described in Step 3, can be seen in Figure 5. Different stakeholders, countries, or individuals will differ in their priorities with respect to the food system outcomes. For example, one could prioritize social equity outcomes over environmental ones. While this is a static figure, the next version of the SFNS visualizer will be able to show this change at a click of a button in an interactive web platform. This will allow for the visualization of different world views, but also to 'play' with the weights given to different performance metrics and see the effects this might have on achieving certain objectives.

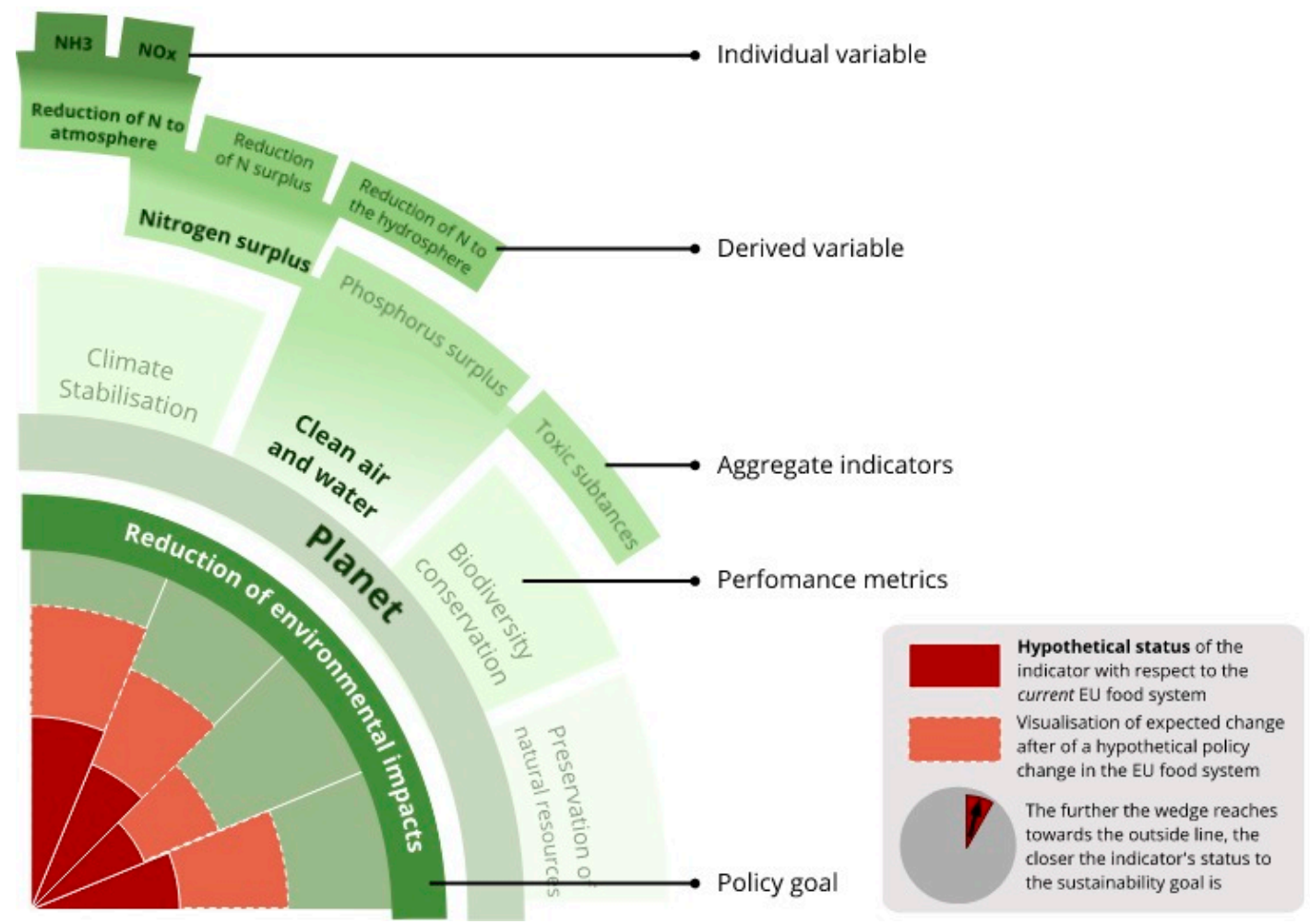

Figure 5. The suggested design for the SFSNS-visualizer when in use. Unfolding the hierarchical approach that underlies a performance metric, in an attempt to make the complexity and assumptions that are embedded in the integrated approach visual to policy-makers or other non-metric experts.

\section{Discussion}

\subsection{Food Systems as 'Transformative Space Making'}

The food systems lens is particularly useful in "making of a transformative space" [58]. As argued elsewhere $[45,46,58]$, transdisciplinary research is increasingly becoming a bridge between the worlds of science and practice, while being highly problem-oriented. The use of an inherently transdisciplinary perspective such as food systems, allows for the convening of people that would otherwise be less likely to enter into discussions about the future of food. The use of the food systems lens, breaking something as complex and dynamic as the food system down into activities, actors and drivers, allows for improved collaboration between stakeholders. This contributes to a mediation of the many different, and sometimes contesting, discourses actors hold about the trajectory of food systems [59]. Consequently, a food systems perspective leads to more effective discussions and an ability to come to a shared understanding.

As this approach is centered on participatory processes, where stakeholders and academics share their ideas about activities and drivers within the system, knowledge about and experience with the diverse food systems components is likely to be varied. Moving through a participatory process to 
map food systems also increases the awareness of complexity and dynamics that are associated with the food system [60]. These characteristics lead us to the argument that the food systems lens is a transformative space making tool.

\subsection{Availability of Indicators and Metrics}

Central to the approach is integration of different types of knowledge and ways of conceiving the food system and its challenges. The move towards incorporation of social equity was the result of an iterative process to co-construct the conceptual framework with the stakeholders. Consultation with food sovereignty experts led to the realization that the availability of social equity or food sovereignty metrics and indicators are less straight forward. While we have started a modest attempt at formulating such metrics, it signals a deeper issue in food systems research. A disconnect between research communities is splitting crucial themes of food systems research between a metrics and modelling-centered side of research and more qualitative equity-centered side of research. Consequently, this has resulted in a disconnect between the two streams, partly explaining the lack of metrics-based food systems assessments that include social equity components [61]. There is an urgent need for research to focus on the conceptualization of social equity assessment mechanisms, as of yet there are only few examples that are moving in this direction $[62,63]$.

There are some obstacles to the formulation of such metrics, such as cross-scale interactions, contextual and situational differences. The global and cross-scale interactions that make up food systems complicate social equity assessment. For example, it is difficult to establish whether the effect of a policy change within EU boundaries is solely responsible for an improvement or deterioration of social equity among food chain actors in a non-EU country. Nevertheless, interaction between the metrics and modelling oriented, and the qualitative equity-centered, research communities is vital for integrated assessment and sustainable development of food systems. Secondly, availability of data remains a common challenge. Data for the EU, especially considering environmental, economic and health data, is generally well documented and readily available via open access statistics. Although, data for seafood is often more difficult to access and is generally treated separately from broader food system issues [47]. For effective assessment of food systems, approaches will need to be available on a global scale [64]. However, the availability of data is political, as it partly relies on strong governance mechanisms to enforce stable monitoring systems and requires overall stable circumstances within a country. Especially when the latter is lacking, as for example could be the case after natural disasters, monitoring and data collection become less of a priority.

\subsection{Learning from the SUSFANS Approach}

Central to the integrated approach is participation of stakeholders, as the entire approach builds on the development of a common framing around food systems. A crucial and difficult first step is the ability to attract a broad group of stakeholders that can represent the different communities and framings (industry, Non-governmental Organizations, consumers, farmers etc.) together with group of academics covering various disciplines. Anyone aspiring to develop a similar integrated approach is required to perform several tasks to create the needed participatory space. This includes the selection of participants that are able to reflect or represent stakeholders for the participatory work; engagement with different mechanisms to get these partners on board and; offering of space for consultation and evaluation that also benefits these partners in some way (be it in gaining a network, or achieving the actual objective of the approach). In other words, the development of a successful integrated approach hinges on the ability to create such a participatory space.

With respect to building an integrated modelling framework the project encountered three different issues with the current selection of models. First, prices (and incomes) driving rational behavior of actors having perfect information (i.e., all and correct information) play a key role in the partial (DIET, CAPRI, GLOBIOM) and general (MAGNET) equilibrium model responses [65]. Thus, prices and income weigh heavily in the quantification of changes in the metrics. Non-price 
considerations (like taste, social norms, convenience, etc.) are partly captured by estimated responses by producers and consumers to changes in prices. Using the elasticities in models, these are then summarized to quantify reactions to potential price changes. In other words, there is a high focus on prices because data on the responses of consumers and producers to non-price incentives are lacking. As such, it is difficult to separate the impact of non-price incentives on consumption patterns and production decision. Complementary analyses on how non-price incentives affect aggregate behavior are needed to be able to assess their implications for the food system. Second, most models cover both the primary producer as the consumer-end of the food system well, while the food chain actors are not very well represented either because the partial equilibrium models (CAPRI, GLOBIOM) define demand in terms of primary products [50,52], focus on the consumer (DIET, SHARP) or have a very aggregated representation of the supply chain (MAGNET) [48,54]. This restricted depiction of the value chain can affect the accuracy of the quantification of a number of performance metrics. This can for example lead to overlooking a number of processes, and therewith miss the associated emissions in the environmental impact calculations. Current data availability and state of research are reflected in these models. It is challenging to address the large heterogeneity that exists across supply chains in applied simulation models. Third, there are a small number of variables-and with that performance metrics-where current models are not able to quantify all variables. This is particularly associated to the goal of 'equitable outcomes and conditions of the EU food system', as this is still novel terrain when it comes to metric development $[61,62,66]$.

Integral to trans-disciplinary science is communication of its results to decision making and policy-makers. This becomes especially important when scientific advice regarding complex dynamic systems, such as a food system, is plural and conditional [67]. In the development of the SFNS-visualizer we have attempted to present the complexity of the food system in a manner that is palatable to a broad audience of decision makers. We were aware of these issues engrained in traditional science-policy communication that are directed at communicating something that is complex in a brief and 'simple' manner. As such, we attempted to design the SFNS-visualizer such that it 'opens up' discussions around food systems, as it will be able to show various states of the system, rather than a single state [68]. It aims to encourage a more informed dialogue rather than one-way, singular science-policy communication.

\section{Conclusions}

The paper has presented an integrated approach to assessing food systems and possible innovations based on a conceptual framework of the EU food system, divided into five steps. There are a number of novelties to this approach: Firstly, this approach is based on a set of integrated performance metrics that allow for assessment of such innovations from various angles, thereby revealing synergies and trade-offs. Secondly, it puts forward a transdisciplinary, multidimensional model that emphasizes usability for a wide range of food system actors. Lastly, it is the first approach that explicitly includes social equity as part of food system assessments: All four components (nutrition and diet, environmental and economic outcomes, and social equity) are essential for an integrated assessment of food systems and development of more sustainable trajectories.

Presented in the paper is the 'SFNS-visualizer' which can show the status of the EU food system with respect to reaching four key policy goals for food system outcomes, as formulated by stakeholders and actors in the system. Brought together in this visualizer are the integrated metrics that are developed based on the designed conceptual framework. These metrics are backed by a modelling strategy that combines several models that span across the food system components. The latter gives way to a 'dynamic' visualizer. The planned final visualizer will be an online tool that allows users to make changes and see the impact of these changes. This contributes to an informed dialogue around desired changes and the possible forms of action to be taken to achieve these.

Lastly, we have highlighted some limitations regarding the food systems assessment that require further research. The first is the development of social equity metrics, due to lack of prior developed 
metrics around the topic and an overall difficulty to obtain data on possible equity indicators. We urgently suggest exploration of social equity metrics development and more broadly, given the lack of data, metrics that can be gathered on a large scale. Secondly, we emphasize the difficulty, but necessity, of communicating the plurality and conditionality of complex, dynamic systems research to an audience of policy-makers. With this paper we have aimed to set a standard for food systems research that provides a starting point for further refinement and development.

Author Contributions: Funding acquisition, T.A.; Investigation, M.Z., A.H., A.L., J.V., M.K., M.G., P.H., T.H., S.H., A.K., L.S., J.M.G., I.T., P.v.V., J.W. and A.Z.; Methodology, M.Z., A.L., M.K. and John Ingram; Project administration, T.A.; Supervision, M.Z.; Visualization, A.H.; Writing-original draft, M.Z., A.H. and M.K.; Writing-review \& editing, M.Z., A.H., A.L., J.V., T.A., M.G., P.H., T.H., S.H., J.I., A.K., L.S., I.T., J.W. and A.Z.

Funding: The research leading to the ideas expressed in this paper has received funding from the European Union's Horizon 2020 framework programme under grant no. 633692 (SUSFANS).

Acknowledgments: We are grateful to all members and advisers of the SUSFANS project, to the participants of four successive workshops of the SUSFANS Stakeholder Core Group between October 2015 and June 2018, and the FOOD 2030 congress (Hohenheim, October 2018) for useful comments and suggestions. The authors would like to thank the anonymous reviewers and Luigi Piemontese for insightful feedback to the paper.

Conflicts of Interest: The authors declare no conflict of interest.

\section{References}

1. Chaudhary, A.; Gustafson, D.; Mathys, A. Multi-indicator sustainability assessment of global food systems. Nat. Commun. 2018, 9, 848. [CrossRef] [PubMed]

2. Rutten, M.; Achterbosch, T.J.; de Boer, I.J.M.; Cuaresma, J.C.; Geleijnse, J.M.; Havlík, P.; Heckelei, T.; Ingram, J.; Leip, A.; Marette, S.; et al. Metrics, models and foresight for European sustainable food and nutrition security: The vision of the SUSFANS project. Agric. Syst. 2018, 163, 45-57. [CrossRef]

3. Foley, J.A.; Ramankutty, N.; Brauman, K.A.; Cassidy, E.S.; Gerber, J.S.; Johnston, M.; Mueller, N.D.; O'Connell, C.; Ray, D.K.; West, P.C.; et al. Solutions for a cultivated planet. Nature 2011, 478, 337-342. [CrossRef] [PubMed]

4. Garnett, T. Where are the best opportunities for reducing greenhouse gas emissions in the food system (including the food chain)? Food Policy 2011, 36, S23-S32. [CrossRef]

5. McKeon, N. Global food governance in an era of crisis: Lessons from the United Nations Committee on World Food Security. Can. Food Stud. 2015, 2, 328. [CrossRef]

6. Gordon, L.J.; Bignet, V.; Crona, B.; Henriksson, P.J.G.; van Holt, T.; Jonell, M.; Lindahl, T.; Troell, M.; Barthel, S.; Deutsch, L.; et al. Rewiring food systems to enhance human health and biosphere stewardship. Environ. Res. Lett. 2017, 12, 100201. [CrossRef]

7. Brunori, G.; Bartolini, F.; Avermaete, T.; Brzezina, N.; Mathijs, E.; Marsden, T.; Faus, A.M.; Sonnino, R.; Hebinck, P.; Oostindie, H.; et al. Creating Resilient Food Systems for Enhancing Food and Nutrition Security; TRANSMANGO: EU KBBE.2013.2.5-01 Grant Agreement No. 613532; TRANSMANGO: Leuven, Belgium, 2017.

8. IPES Food. The New Science of Sustainable Food Systems: Overcoming Barriers to Food Systems Reform; IPES Food: Brussels, Belgium, 2015. Available online: http:/ / www.ipes-food.org/reports (accessed on 15 November 2018).

9. Milan Expo. Milan Urban Food Policy Pact; Milan Expo: Milan, Italy, 2015. Available online: http://www. milanurbanfoodpolicypact.org/ (accessed on 15 November 2018).

10. Duncan, J. “Greening” global food governance. Can. Food Stud. 2015, 2, 335. [CrossRef]

11. Haysom, G. Food and the city: Urban scale food system governance. Urban Forum 2015, 26, $263-281$. [CrossRef]

12. Lang, T.; Barling, D. Food security and food sustainability: Reformulating the debate. Geogr. J. 2012, 178, 313-326. [CrossRef]

13. Lang, T.; Barling, D.; Caraher, M. Food Policy: Integrating Health, Environment and Society; Oxford University Press: Oxford, UK, 2009; ISBN 0191015717.

14. Candel, J.J.L.; Pereira, L. Towards integrated food policy: Main challenges and steps ahead. Environ. Sci. Policy 2017, 73, 89-92. [CrossRef]

15. Ingram, J. A food systems approach to researching food security and its interactions with global environmental change. Food Secur. 2011, 3, 417-431. [CrossRef] 
16. Ericksen, P.J. Conceptualizing food systems for global environmental change research. Glob. Environ. Chang. 2008, 18, 234-245. [CrossRef]

17. Ericksen, P.J. What is the vulnerability of a food system to global environmental change? Ecol. Soc. 2008, 13, 14. [CrossRef]

18. CFS. Coming to Terms with Terminology_Food and Nutrition Security; Thirty-Ninth Session, Item V.a; Commitee on World Food Security: Rome, Italy, 2012. Available online: http:/ / www.fao.org/docrep/meeting/026/ MD776E.pdf (accessed on 15 November 2018).

19. Pangaribowo, E.H.; Gerber, N.; Torero, M. Food and Nutrition Security Indicators: A Review. Available online: https:/ / www.wecr.wur.nl/WECRGeneral/FoodSecurePublications/05_Pangaribowo\%20Gerber\% 20Torero_FNS\%20Indicators.pdf (accessed on 15 November 2018).

20. Pinstrup-Andersen, P. Food security: Definition and measurement. Food Secur. 2009, 1, 5-7. [CrossRef]

21. Sen, A. Hunger and Entitlements; World Institute for Development Economics Research: Helsinki, Finland, 1987; ISBN 9519991506.

22. Sen, A. Poverty and Famines: An Essay on Entitlement and Deprivation; Clarendon Press: New York, NY, USA; Oxford, UK, 1981; ISBN 0198284632.

23. Acharya, T.; Fanzo, J.; Gustafson, D.; Ingram, J.S.I.; Schneeman, B. Assessing Sustainable Nutrition Security: The Role of Food Systems; The International Life Sciences Institute, Research Foundation, Center for Integrated Modeling of Sustainable Agriculture and Nutrition: Washington, DC, USA, 2014.

24. Gustafson, D.; Gutman, A.; Leet, W.; Drewnowski, A.; Fanzo, J.; Ingram, J. Seven food system metrics of sustainable nutrition security. Sustainability 2016, 8, 196. [CrossRef]

25. Allen, T.; Prosperi, P. Metrics of Sustainable Diets and Food Systems; Workshop Report; Bioversity International \& CIHEAM-IAMM: Montpellier, France, 2014.

26. Fischer, C.G.; Garnett, T. Plates, Pyramids and Planet; FAO; The Food Climate Research Network at The University of Oxford: Oxford, UK, 2016; ISBN 9789251092224.

27. Lukas, M.; Rohn, H.; Lettenmeier, M.; Liedtke, C.; Wiesen, K. The nutritional footprint-Integrated methodology using environmental and health indicators to indicate potential for absolute reduction of natural resource use in the field of food and nutrition. J. Clean. Prod. 2016, 132, 161-170. [CrossRef]

28. Ranganathan, J.; Vennard, D.; Waite, R.; Dumas, P.; Lipinski, B.; Searchinger, T. Shifting Diets for a Sustainable Food Future; Installment 11 of "Creating a Sustainable Food Future"; World Resources Institute: Washington, DC, USA, 2016.

29. Lang, T.; Heasman, M. Food Wars: The Global Battle for Mouths, Minds and Markets; Earthscan: London, UK, 2004.

30. Jones, A.D.; Hoey, L.; Blesh, J.; Miller, L.; Green, A.; Shapiro, L.F. A Systematic Review of the Measurement of Sustainable Diets. Adv. Nutr. Int. Rev. J. 2016, 7, 641-664. [CrossRef] [PubMed]

31. Gussow, J.D. Mediterranean diets: Are they environmentally responsible? Am. J. Clin. Nutr. 1995, 61, S1383-S1389. [CrossRef] [PubMed]

32. Tendall, D.M.; Joerin, J.; Kopainsky, B.; Edwards, P.; Shreck, A.; Le, Q.B.; Kruetli, P.; Grant, M.; Six, J. Food system resilience: Defining the concept. Glob. Food Secur. 2015, 6, 17-23. [CrossRef]

33. FAO. Climate Change and Food Security: A Framework Document; Food and Agriculture Organization of the United Nations: Rome, Italy, 2008.

34. Ingram, J.; Ericksen, P.; Liverman, D. Food Security and Global Environmental Change; Earthscan: London, UK; Washington, DC, USA, 2010.

35. Foran, T.; Butler, J.R.A.; Williams, L.J.; Wanjura, W.J.; Hall, A.; Carter, L.; Carberry, P.S. Taking complexity in food systems seriously: An interdisciplinary analysis. World Dev. 2014, 61, 85-101. [CrossRef]

36. Brinkley, C. Avenues into food planning: A review of scholarly food system research. Int. Plan. Stud. 2013, 18, 243-266. [CrossRef] [PubMed]

37. Prosperi, P.; Allen, T.; Cogill, B.; Padilla, M.; Peri, I. Towards metrics of sustainable food systems: A review of the resilience and vulnerability literature. Environ. Syst. Decis. 2016, 36, 3-19. [CrossRef]

38. Lehtonen, M.; Sébastien, L.; Bauler, T. The multiple roles of sustainability indicators in informational governance: Between intended use and unanticipated influence. Curr. Opin. Environ. Sustain. 2016, 18, 1-9. [CrossRef]

39. Global Panel. Improved Metrics and Data Are Needed for Effective Food System Policies in the Post-2015 Era; Technical Brief; Global Panel on Agriculture and Food Systems for Nutrition: London, UK, 2015. 
40. Lehtonen, M. Indicators: Tools for informing, monitoring or controlling? In The Tools of Policy Formulation: Actors, Capacities, Venues and Effects; Jordan, A.J., Turnpenny, J.R., Eds.; Edward Elgar Publishing Ltd.: Cheltenham, UK, 2015; pp. 76-99. ISBN 9781783477036.

41. Zurek, M.; Ingram, J.; Zimmermann, A.; Garrone, M.; Rutten, M.; Tetens, I.; Leip, A.; Veer, P.; Verain, M.; Bouwman, E.; et al. D1.1 A Framework for Assessing and Devising Policy for Sustainable Food and Nutrition Security in EU: The SUSFANS Conceptual Framework; SUSFANS, GA No. 633692; SUSFANS: The Hague, The Netherlands, 2016.

42. Zurek, M.; Leip, A.; Kuijsten, A.; Wijnands, J.; Terluin, I.; Shutes, L.; Hebinck, A.; Zimmermann, A.; Götz, C.; Hornborg, S.; et al. D1.3 Sustainability Metrics For The EU Food System: A Review Across Economic, Environmental And Social Considerations; SUSFANS, GA No. 633692; SUSFANS: The Hague, The Netherlands, 2017.

43. Kuiper, M.; Zurek, M.; Havlik, P.; Deppermann, A.; Valin, H.; Kuijsten, A.; Geleijnse, M.; Veer, P.; Heckelei, T.; Götz, C.; et al. A Modelling Strategy for Quantifying the Sustainability of Food and Nutrition Security in the EU: Deliverable 1.4; SUSFANS, EU Grant Agreement 633692; SUSFANS: The Hague, The Netherlands, 2017.

44. Zurek, M.; Hebinck, A.; Leip, A.; Achterbosch, T.; Garrone, M.; Havlik, P.; Heckelei, T.; Ingram, J.; Soler, L.G.; van't Veer, P.; et al. D1.5 An Inegrated Set of Metrics for Assessing the Overall Sustainability of Food and Nutrition Security in the EU; SUSFANS, GA No. 633692; SUSFANS: The Hague, The Netherlands, 2017.

45. Pereira, L.; Karpouzoglou, T.; Doshi, S.; Frantzeskaki, N. Organising a safe space for navigating social-ecological transformations to sustainability. Int. J. Environ. Res. Public Health 2015, 12, 6027-6044. [CrossRef] [PubMed]

46. Hebinck, A.; Vervoort, J.M.; Hebinck, P.; Rutting, L.; Galli, F. Imagining transformative futures: Participatory foresight for food systems change. Ecol. Soc. 2018, 23, 16. [CrossRef]

47. Farmery, A.K.; Gardner, C.; Jennings, S.; Green, B.S.; Watson, R.A. Assessing the inclusion of seafood in the sustainable diet literature. Fish Fish. 2017. [CrossRef]

48. Woltjer, G.; Kuiper, M.; Kavallar, A.; van Meijl, H.; Powell, J.; Rutten, M.; Shutes, L.; Tabeau, A. The MAGNET Model: Module Description; LEI Report No. 14-057; LEI—Wageningen UR: Wageningen, The Netherlands, 2014.

49. Irz, X.; Leroy, P.; Réquillart, V.; Soler, L.G. Economic assessment of nutritional recommendations. J. Health Econ. 2015. [CrossRef] [PubMed]

50. Britz, W.; Van Ittersum, M.; Lansink, A.O.; Heckelei, T. Tools for integrated assessment in agriculture. State of the art and challenges. Bio-Based Appl. Econ. 2012, 1, 125-150. [CrossRef]

51. Leip, A.; Britz, W.; Weiss, F.; De Vries, W. Farm, land, and soil nitrogen budgets for agriculture in Europe calculated with CAPRI. Environ. Pollut. 2011, 159, 3243-3253. [CrossRef] [PubMed]

52. Havlik, P.; Valin, H.; Herrero, M.; Obersteiner, M.; Schmid, E.; Rufino, M.C.; Mosnier, A.; Thornton, P.K.; Bottcher, H.; Conant, R.T.; et al. Climate change mitigation through livestock system transitions. Proc. Natl. Acad. Sci. USA 2014, 111, 3709-3714. [CrossRef] [PubMed]

53. Havlík, P.; Schneider, U.A.; Schmid, E.; Böttcher, H.; Fritz, S.; Skalský, R.; Aoki, K.; De Cara, S.; Kindermann, G.; Kraxner, F.; et al. Global land-use implications of first and second generation biofuel targets. Energy Policy 2011. [CrossRef]

54. Irz, X.; Leroy, P.; Réquillart, V.; Soler, L.-G. Beyond wishful thinking: Integrating consumer preferences in the assessment of dietary recommendations. PLoS ONE 2016, 11, e0158453. [CrossRef] [PubMed]

55. Rutten, M.; Zimmermann, A.; Havlík, P.; Leip, A.; Heckelei, T.; Achterbosch, T. D9.1 Modelling Sustainability and Nutrition in Long Run Analyses of the EU Agri-Food system: Work plan for the SUSFANS Toolbox; SUSFANS, GA No. 633692; SUSFANS: The Hague, The Netherlands, 2016.

56. Kuiper, M.; Oudendag, D.; Bartelings, H.; Shutes, L.; Verma, M.; Tabeau, A. D9.2 Enhanced Modelling of Sustainable Food and Nutrition Security: Food Consumption and Nutrition Behaviour of European Households; SUSFANS, GA No. 633692; SUSFANS: The Hague, The Netherlands, 2017.

57. Galafassi, D.; Daw, T.M.; Munyi, L.; Brown, K.; Barnaud, C.; Fazey, I. Learning about social-ecological trade-offs. Ecol. Soc. 2017, 22, 1-27. [CrossRef]

58. Marshall, F.; Dolley, J.; Priya, R. Transdisciplinary research as transformative space making for sustainability: Enhancing propoor transformative agency in periurban contexts. Ecol. Soc. 2018, 23, 1-13. [CrossRef]

59. Clapp, J. Food security and food sovereignty: Getting past the binary. Dialogues Hum. Geogr. 2014, 4, $206-211$. [CrossRef]

60. Galafassi, D.; Daw, T.M.; Thyresson, M.; Rosendo, S.; Chaigneau, T.; Bandeira, S.; Munyi, L.; Gabrielsson, I.; Brown, K. Stories in social-ecological knowledge cocreation. Ecol. Soc. 2018, 23. [CrossRef] 
61. Weiler, A.M.; Hergesheimer, C.; Brisbois, B.; Wittman, H.; Yassi, A.; Spiegel, J.M. Food sovereignty, food security and health equity: A meta-narrative mapping exercise. Health Policy Plan. 2015, 30, 1078-1092. [CrossRef] [PubMed]

62. Landert, J.; Schader, C.; Moschitz, H.; Stolze, M. A holistic sustainability assessment method for urban food system governance. Sustainability 2017, 9, 490. [CrossRef]

63. Dixon, J.; Omwega, A.M.; Friel, S.; Burns, C.; Donati, K.; Carlisle, R. The health equity dimensions of urban food systems. J. Urban Health 2007, 84. [CrossRef] [PubMed]

64. Open Data Institute. How Can We Improve Agriculture, Food and Nutrition with Open Data? 2015. Available online: https: / www.godan.info/documents/how-can-we-improve-agriculture-food-and-nutrition-open-data (accessed on 15 November 2018).

65. Valin, H.; Sands, R.D.; van der Mensbrugghe, D.; Nelson, G.C.; Ahammad, H.; Blanc, E.; Bodirsky, B.; Fujimori, S.; Hasegawa, T.; Havlik, P.; et al. The future of food demand: Understanding differences in global economic models. Agric. Econ. 2014. [CrossRef]

66. James, S.W.; Friel, S. An integrated approach to identifying and characterising resilient urban food systems to promote population health in a changing climate. Public Health Nutr. 2015, 18, 2498-2508. [CrossRef] [PubMed]

67. Stirling, A. Keep it complex. Nature 2010, 468, 1029-1031. [CrossRef] [PubMed]

68. Leach, M.; Scoones, I.; Stirling, A. Dynamic Sustainabilities: Technology, Environment, Social Justice; Earthscan: London, UK, 2010; ISBN 1849775060.

(C) 2018 by the authors. Licensee MDPI, Basel, Switzerland. This article is an open access article distributed under the terms and conditions of the Creative Commons Attribution (CC BY) license (http:/ / creativecommons.org/licenses/by/4.0/). 